\title{
Futebol - gesto poético
}

\author{
Football - poetic gesture
}

Antonio Jardim

Universidade Federal do Rio de Janeiro (UFRJ), Rio de Janeiro / Brasil

Doutor em Letras, UFRJ

antoniojjardim@gmail.com

Resumo: Esta obra entende o futebol como um gesto poético, no mesmo sentido que um gesto poético é o gesto principal da arte, pertencente à vida. Ou seja: um gesto poético mostra e diz-se, a partir do real, e apenas a partir da bola.

PalaVras-chave: Futebol; Filosofia; Poético; Linguagem; Memória.

ABSTRACT: This work understands football as a poetic gesture, in the same sense that a poetic gesture is the main gesture of art, pertaining of life. That is: a poetic gesture shows and says itself, from the real, and only from the ball.

KEYwords: Football; Philosophy; Poetic; Language; Memory. 
Não é pra falar das paixões... é apenas para vivê-las. Antonio Jardim

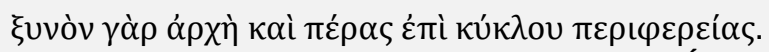
Heráclito de Éfeso

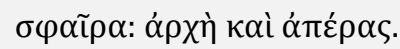
Ignorado de Laranjeiras

Futebol é único jogo desde real, o resto...

Para Priscila Loureiro pela oferta do tema

Jogar sem bola é o título desse evento que tematiza um encontro inesperado, o do futebol, apresentado como tema para concepções e com algumas formulações teóricas que aqui se apresentam. Para fazer uma impertinência inicial precisaremos começar dizendo que partiremos da compreensão que, sem bola podemos jogar muita coisa, menos futebol. Pois futebol é a articulação essencial de pé e bola, ou melhor, de bola e pé, como depois talvez compreendamos.

Quando convidado a realizar este trabalho, que ora se apresenta, o entendimento que me ocorreu inicialmente foi "Futebol: gesto poético constituidor de memória". A perspectiva, portanto é tratar o tema de modo que possamos tentar sair das abordagens que mais costumeiramente se apresentam sem saber se teremos êxito nessa empreitada. Provavelmente não.

Futebol é, tal como o entendo, antes que outra qualquer coisa, gesto. Não qualquer gesto, mas sempre um gesto originário capaz de articular memória, de inscrever-se na memória que, por sua vez, se constitui desde um presente até o passado possibilitando um gesto em direção ao futuro.

Como sentido, o gesto originário, o gesto poético, é o componente inaugural do que pode ser uma dimensão originária de linguagem. É desse modo que se inicia uma possibilidade de relacionamento entre futebol e filosofia.

A palavra filosofia, por sua vez, é compreendida geralmente numa acepção recente e mais comum, genérica, como amar o saber, amor à sabedoria. No entanto, há a possibilidade de a compreendermos mais remotamente. A palavra grega $\varphi$ í̉oৎ (phylos) diz arcaicamente daquilo que é próprio, nesse sentido, é um possessivo 
que prescinde de posse subjetiva, pois o próprio é uma outorga que todo e qualquer fenômeno é capaz de trazer consigo; já a palavra oọía (sophia), vem nos trazer não uma experiência genérica com todo e qualquer saber, mas um saber, aquele saber que é capaz de nos trazer o conhecimento do que é integro, e integrante enquanto íntegro, da cultura grega ou qualquer outra, o saber do poeta, do criador. Assim, trataremos filosofia aqui como o que é capaz de, enquanto próprio, desencadear o poético e não um conjunto de conceitos tratados por uma história da filosofia ocidental, como é mais comum. Precisamos nos lembrar que a palavra poesia ou, como tratamos aqui, a dimensão poética, é dita em grego

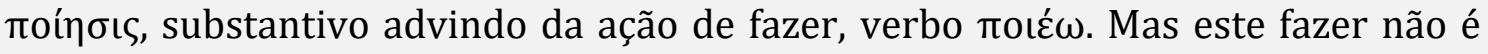
um qualquer fazer e sim um fazer originário que possa ser compreendido como criação - aqui entendida como instauração de espaço-temporalidade.

Dentre estes esclarecimentos iniciais precisamos ainda dizer que compreendemos linguagem aqui, destituída de qualquer presença humana, que se coloque como instaurador dela. Linguagem aqui não poderá ser compreendida como uma interação comunicativa entre sujeitos, ou entre um sujeito e um objeto.

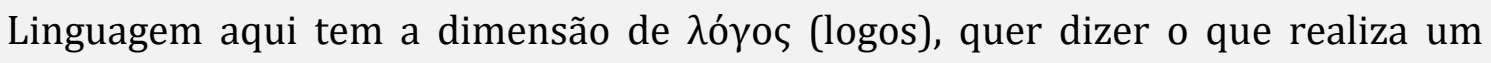
$\varphi \alpha ı$ ó $\mu \varepsilon v o v$, palavra que tendo em si os verbos $\varphi \varepsilon \mu i ́$ (phemí) e $\varphi \alpha i ́ v \omega$ (pháino), congrega todo dizer-se que se mostra e todo mostrar-se que se diz. Assim, vamos aqui entender como movimento essencial da linguagem todo dizer-se que enquanto dizer-se se mostra e todo mostrar-se que enquanto mostrar-se é capaz de se dizer, de dizer si-mesmo.

Precisamos ainda ressaltar a forma impessoal como esses dizer-se e mostrar-se são capazes de se realizarem. Essa forma impessoal no grego é dita pela voz média, a voz do que não é agente nem, muito menos, paciente. Linguagem é o fenômeno que, advindo do real, é capaz de mostrar-se e dizer-se impessoalmente desde este real para este mesmo real, de modo que todo gestualizar do real é um movimento essencial da linguagem. Os gregos entendiam o modo de se dizer do movimento do ser como uma voz média, como foi acima dito, significa, uma voz sem agente nem paciente, uma voz das coisas, por assim dizer.

Linguagem é, portanto, todo gesto de real que é capaz de fazer eclodir real, todo gesto fenomênico que faz eclodir fenômeno, todo gesto que sendo presença 
faz eclodir presente, passado e futuro, não necessariamente como dimensões sucessivas e causais, e sim em simultaneidade, criando uma intratemporalidade constituidora de memória; memória no presente, desde o passado e até o futuro, em que essas dimensões - passado, presente e futuro - desaparecem no ato memorável, por isso o gesto poético é sempre um gesto intratemporal em que o tempo não é linear nem sucessivo. Essa intratemporalidade aqui não quer, de nenhum modo, dizer que o gesto poético nasce dentro de um tempo previamente estabelecido, pelo contrário esse intratempo, entretempo é, para que seja poético, co-existente a esta mesma temporalidade. 0 gesto poético é fundador de uma intratemporalidade que intrapõe tempo e espaço numa só presentificação. 0 gesto poético não tem origem num passado que se prorroga em presente e futuro,é íntegro, não sofre das presunções do ex-acto, do fora do ato. É sempre uma presença que se ex-pera, que se põe num des-limite, num ex-peiro. Uma ex-pera que congrega o inesperado como condição que todo o limite traz consigo surpreenderse com o que traz de inesperado, o des-limite. Heráclito nos dizia:

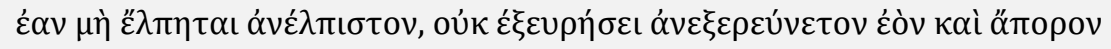
(ean mè élpetai anélpiston, ouk exeurései anexeréuneton eon kaì áporon).

Se não espera inesperado, não descobre encoberto próprio, ou o próprio do encoberto, e não há travessia, não comparece transitividade. ${ }^{1} 0$ que vai nos dizer, na sabedoria de Heráclito, que todo esperar conduz tanto ao que se espera quanto ao que nunca se haveria de esperar. 0 movimento intratemporal estaria nessa transitividade e sempre é proporcionado pelo inesperado. A intratemporalidadeintraespacialidade é a condição de que em toda espera possa eclodir o inesperado, é algo que pode instaurar um tempo-espaço próprio, desde o próprio, isto é, o nunca dantes instaurado. O tempo-espaço do inesperado é tão próprio como inusitado. Não admite causalidades nem linearidades. Um gesto originário se inscreve, reinventa, pro-duz, pro-ducere, nos leva a perceber o que se põe, o que se presentifica, o que se mostra e se diz, sem pré-vias, estatuto essencial do que se

\footnotetext{
${ }^{1}$ Transcrições e traduções livres do autor do texto.
} 
põe linguagem, desde o mostrar-se e dizer-se sem sujeição aos estatutos prescritivos de um pré-existente, de uma pré-via. Os estatutos do pré-existente acabam por serem prescritivos, e o prescritivo do pré-existente só articula a memória como linearidade e causalidade, jamais será gesto inaugural.

Um gesto para ser inaugural precisa criar um espaço-tempo, só assim é

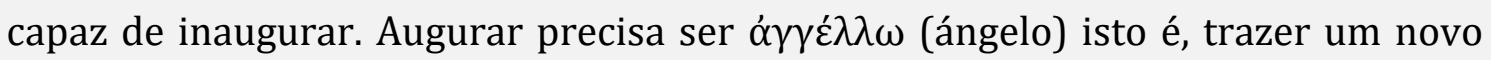
modo de fazer saber, assim, todo conhecimento traz consigo, em seu gesto inaugural, o desconhecido e desconhecimento. Todo saber é impositivo de não saber. Não é possível saber o que já se sabe, só é possível saber o que ainda não se sabe, só assim o saber tem sabor e faz-se em sua essencialidade como um saber saboroso e assim só pode partir do ainda não sabido. Não é ex-acto, não pode ser fora do ato, ao contrário é sobretudo ato, agir, agenciamento primeiro e inaugural. Não é uma concepção, é sempre um gesto, só assim é verdadeiro, não pode ser juízo de juízes precipitados e precipitadores, não pode ser uma prescrição para ação, ao inverso, é sempre ação originária. Ações originárias são des-velações, desvelamentos, assim, instauram a verdade pré-propositiva, pré-predicativa. Não mera adequação entre dito e coisa, mas entendendo o gesto coisal, o ato percebe que não há verdade sem ato, nunca haverá verdade no ex-acto. Nunca haverá verdade fora de um gesto originário. Não é possível conhecimento sem a inaugurabilidade do gesto. Impossível se pensar em formação sem o gesto capaz de produzir encanto. Não há memória sem encanto. A memória é constituição a partir do gesto originário. No previsto a memória é apenas vaga lembrança, recordação e não aciona verdade. Nunca é capaz de instaurar o que não pode deixar de ser memória, quer dizer, a experiência, o deslimite que faz do memorável um ato e jamais o ex-acto. A memória é a con-dicção do ato. Ela é o ato que responde ao ato. A res-posta que responde à res. A coisa que responde à coisa. A memória con-diz ato, não con-duz.

Como con-dicção de ato, ela, memória o pro-cura, cuida dele, cura ato. Dele, ato, nunca pode prescindir. Sem ato não é possível ex-acto. Con-dizer-se ao ato demanda o ato inaugural. Demanda um ato que esteja além do factual, demanda um acontecimento. Um acontecer diz de uma experiência de tanger cuja raiz é teg que se coloca também em in-teg-ro, tocar é integrar, assim acontecer é tocar algo 
que se manifesta como acto, como agir, como agenciar, em que o agente diz alguma coisa que não é sujeito, no sentido moderno, mas está sujeito, sub-jectum, ao que se manifesta desde um lugar sub-jacente. Esse desde baixo, de sub, não é inferioridade, ao inverso, diz presença desde algum lugar, isto é, desde o lugar tempo-espaço - em que é possível manifestação. O lugar de onde provêm todas as manifestações é o ser, o real, o tempo-espaço daquilo que é.

0 real é o des-afio, é desde onde se desfia o fio - a trama, o drama. Drama provém de $\delta \rho \alpha ́ \omega$ que diz agir. Trama é proveniente de trans-meare através da meada, desde a meada, relativo a entregar, passar adiante, dare, dar. Mas o que se daria numa trama? Numa trama se dá um gesto de real em resposta a outro gesto de real. Assim, toda trama é dramática, é acionada e acionante a um só tempoespaço. Todo drama é tramático e toda trama é dramática. Ambas, trama e drama são acionamentos desde o real a que o real necessita responder.

O drama de Penélope é fiar e desfiar a trama no aguardo de Odisseus. 0 drama res-ponde à trama. A trama aciona o drama. Penélope não se permite a inação, o ex-acto. Pelo contrário, o real impõe o real. Sua ação não é linear nem causal. 0 drama alimenta a trama. A trama res-ponde o drama. Fazer e desfazer, esse é sempre o drama, essa é sempre a trama do real.

Em seu fragmento 123, é ainda Heráclito quem nos auxilia:

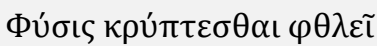

Physis kríptestai phyléi

Ser oculta-se sendo.

O próprio do ser é mostrar-se enquanto o que se presentificando se oculta, quer dizer, o ser impõe des-velar-se o seu drama é sua trama. Sua ação é a ação de tramar, fiar e des-fiar, des-ser, isto é, negação do ser.

Essa trama é a trama e o drama da linguagem, do lógos. 0 lógos é o lugar do fiar e desfiar, isso pretende dizer que esse mostrar-se e dizer-se é desde o real para o real. Linguagem não é meio para, é con-dicção. É a dicção que con-diz real, não com a neutralidade de um meio, não desde um juizo, mas desde o gesto decisivo de dizer com, con-dizer-se. 
Como seria possível essa ação de dizer-se para si mesmo de modo a suspender os ajuizamentos? A linguagem não seria precisamente um meio para os ajuizamentos? Precisamente sim! Mas não se trata de precisão. Não se trata de certeza e sim de verdade. A questão que está posta desde o real é sempre a questão da verdade, e somente sendo desde a verdade é que a certeza pode ter algum vigor ainda que provisório. Uma questão é filosófica não desde a verdade como juízo certeza - e sim desde a verdade como gesto de real.

Um gesto de real não é mais nem menos co-rrecto. Ninguém ousaria dizer que o sol ou a chuva são mais ou menos verdade, o que se pode afirmar é se são desejáveis ou indesejáveis num momento ou no outro. Juízos dependem de nós, a verdade nunca. A verdade é, em sua dinâmica, articulação do ser, do real. 0 ser é, se é, ou não é, se não é. 0 real não inquere por desejos, ele se manisfesta em seu movimento. Se nos fosse dado escolher, nenhum cataclisma ocorreria. Abominamos os acidentes que nos aterrorizam, quer dizer aqueles que manifestam terra (entendida aqui como o que resume terra, ar, água ou fogo). 0 que vem da terra não pede licença a nada nem a ninguém. 0 que vem da terra é, simplesmente é. A terra desaponta os juízes e as leis. 0 que é, não é uma de-cisão, enquanto um perpetrar de uma vontade. Os seres vivos têm vontade, mas sua vida está além ou aquém de sua vontade. A máxima da verdade é ser oculta-se, sendo desse modo o que é independe das vontades ou juízos. A máxima da vontade é, ser é o que eu desejo. Muita alegria e pouco saber foi dado aos mortais, nos diz Hölderlin. Parafrasearíamos dizendo: aos mortais é possível o querer, mas este sendo uma parcela do ser nunca será capaz de tramá-lo inteiramente.

Nossa questão é se futebol é gesto, que gesto seria esse? Seria um gesto previsto? Previsível? Seria isso o futebol, um conjunto de gestos previsíveis? A resposta imediata é sim. Seria isso. Suas táticas, suas regras, seus esquemas, a cada dia mais presentes e passíveis de um furor analítico que chega a converter em estatísticas o rendimento coletivo e individual de seus praticantes, na ânsia de compreender como se joga o jogo, como se estabelece a superioridade de um dos dois times.

Assim, no futebol, em sua versão mais recente, se buscam e se encontram certezas. Tudo que vale no futebol hoje são as artimanhas de um intelecto que o 
planeja mas não joga. Aceitar o desafio da trama, do drama? Jamais! Há metas a cumprir, dividendos para auferir. Os objetivos lançam-se como construídos com sucesso por extraordinárias subjetividades iluminadas - dessas fazem parte a mídia esportiva, e os corpos de técnicos e até mesmo praticantes convencidos pelo ex-acto. 0 ex-acto trucida o gesto, mas o futebol sobrevive, apesar de tudo isso. Apesar dos esfacelamentos intelectuais e na maior parte pseudo-intelectuais. Desgraça sem graça, cada vez mais sem graça. Mas ainda persistem algumas graças. Graças aos gestos que não são representações de gestos, são concretos, são cataclismas, são verdade e nunca apenas as certezas das estatísticas.

Cabe aqui um pequeno desvio nessa trama, nesse drama. Estatísticas, médias são sempre a maneira de tentar fazer de um projeto, o concreto. As médias são uma maneira óbvia de se tentar dizer a certeza como verdade. Por exemplo, um professor avalia seu aluno em duas avaliações, ele tirou oitoem sua primeira nota e nove na segunda; logo sua média é oito e meio, a nota que concretamente jamais tirou, na prova que nunca fez. As médias constituidoras das estatísticas funcionam desde o ex-acto, no ex-acto para o ex-acto. Este simulacro de verdade tem aparência de incontestável, afinal é exato, ex-acto. As matemáticas se apropriaram do conhecimento a partir desse tipo de argumentação que tem aparência infalível. Afinal, se a operação está certa, o que não estaria? As matemáticas várias acenam com a precisão, não com o concreto.

Retornando ao tema: a nossa questão ao pensarmos uma atividade que é sobretudo gesto, ato, gesto inaugurador, é tentar entender como se dá a sobrevivência do ato, da verdade, em tempos cuja regra é praticar o ex-acto, pela certeza. Certa vez, Nietzsche nos tentou advertir e alertar para isso dizendo que toda a ciência ocidental era completamente moral. 0 sentido disso em Nietzsche era o seu entendimento que a certeza - binarização da verdade - ao assumir a posse da verdade passa a se mover e a nos mover no interior de operações onde existe apenas o certo e o errado, princípio de moralidade. E Nietzsche nos indica a arte - gesto inaugurador - como a possibilidade de escapar desse moralismo, fazendo-nos prestar atenção nos gestos de real, novamente. 
No futebol, assim como na arte, o gesto inaugural augura outras vigências, outros vigores. Esses vigores asseguram a vida, apesar de cada vez mais serem difíceis de serem percebidos.

É ainda com Heráclito de Éfeso, que insistimos, quando ele nos apresenta a sua sabedoria:

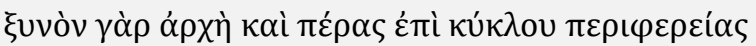
(Xynòn gar arché kaì péras epì kyklou periferéias).

Na mesma circunferência (periferia, cercania) princípio e limite (fim, como limite, não como finalidade).

Que um autor ignorado provavelmente parafraseou em:

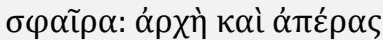

$$
\begin{aligned}
& \text { (sfaîra: arché kaì apéras) } \\
& \text { esfera: princípio e des-limite. }
\end{aligned}
$$

Tanto em Heráclito como no Ignorado de Laranjeiras, que denominaremos doravante de Ignorado, vemos, na circunferência num, e na esfera no outro, a consumação de princípio e fim, aqui compreendido não como finalidade, mas como limite. Todo princípio é inaugural e augura limite que vez por outra se faz passar por fim, por finalidade, sem que de fato seja. Limite é con-dicção de princípio. Não há princípio sem limite. 0 princípio é con-diccionado pelo limite sine qua non. Sem limite o princípio seria absoluto e cessaria seu movimento, seu gesto.

No futebol a con-dicção sine qua non é o gesto, mas que gesto? 0 gesto humano? O gesto do jogador, dos times, da torcida? Não, esses são gestos de mundo, e são importantes, muito importantes, mas haveria futebol sem eles. Estes são gestos de mundo quer dizer gestos dependentes de um gesto primeiro, tal como aqui tento entender. Um gesto de mundo é um gesto que parte da noção

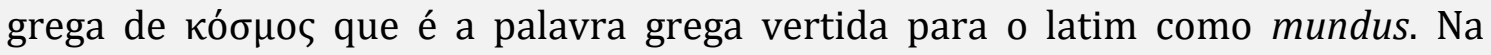

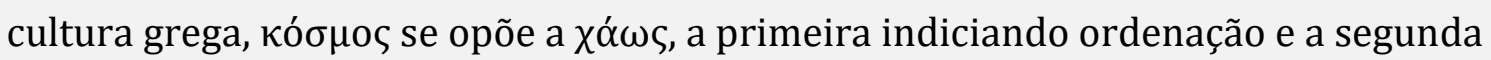
desordem. A cultura latina as traduziu como pode em mundus e i-mundus. Assim, mundo ordena, mundifica, modifica o imundo, o desordenado. Na relação que o 
homem estabelece com o real, este não cumpre ordens. Sua natureza é ser, sendo ser oculta-se sendo, esta é a máxima - dessa maneira, o gesto de mundo é sempre um gesto de real, mas a recíproca não é linearmente verdade. Verdade é real, mundo é certeza ou erro. 0 gesto inaugural é de real, não mundano, este é aquele com o limite da ordenação. Na ordem do mundo o real se re-colhe, mas nunca desaparece. 0 real colhe e é colhido pelo gesto do que é, sendo o seu próprio gesto, que nunca é, de imediato, um gesto, necessariamente, mundanizador, ainda que não exclua a possibilidade do mundano.

Retornemos até Éfeso e ouçamos novamente Heráclito:

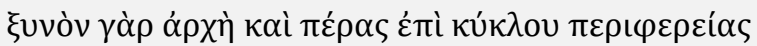

(Xynòn gar arché kaì péras epì kyklou periferéias)

O comum: princípio e limite na circunferência do círculo.

Consumação na possibilidade instaurada pela circunferência do círculo. Nesta, princípio e limite comparecem sem que seja possível uma distinção articulada pelo ex-acto. Ninguém pode dizer num círculo onde se encontram ou onde se separam princípio e limite. Imagine se seria possível isto quando se instauram uma infinidade de círculos como nos adverte nosso pensador Ignorado de Laranjeiras, quando nos diz:

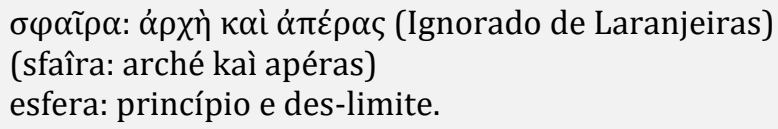

Acima afirmamos que todo o princípio carrega consigo limite e aqui completamos que todo limite, por carregar consigo princípio, instaura deslimite. 0 limite é portador do des-limite, isto é, todo limite traz consigo a possibilidade de transgredir seu limite, sem que, no entanto, seja capaz de aboli-lo inteiramente. $\mathrm{Na}$ constante articulação humana de homem e real, o homem nunca é, substantivamente, fora do real. Homem é sempre homem no real inscrevendo mundo e inscrevendo-se neste. A trama humana é o drama desta relação originária. Os gestos de mundo são gestos de real, ainda que nem todo gesto de real seja necessariamente um gesto de mundo. Gestos de mundo só são inaugurais 
porque e quando trazem consigo gestos de real. Em todos os jogos, esportivos ou não, que aqui tratamos e trataremos num binômio trama-drama, os gestos se confundem muitas vezes, mas nunca se tornam impossiveis de serem compreendidos. Aliás, essa é a nossa esperança fundamental neste trabalho. É preciso que possamos tentar compreender sempre como somos nos mundos que habitamos e, porque os habitamos, os construimos.

Jogos são muitos. Jogos de toda a espécie. Achamos que jogamos, achamos sobretudo que jogamos uns com os outros, uns contra outros. Isso é certo. Com certeza jogamos. Mas jogar com o real é mais que certeza, é jogar desde nossa constante tentativa de surpreender o inesperado.

Novamente nos localizamos em Éfeso e Heráclito que nos diz, mais uma vez:

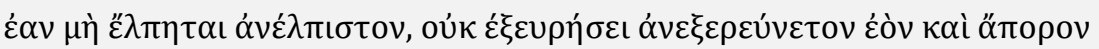
(ean mè élpetai anélpiston, ouk exeurései anexeréuneton eon kaì áporon).

Se não espera inesperado, não descobre encoberto próprio, ou o próprio do encoberto, e não há travessia, não comparece transitividade. Surpreender o inesperado não é adivinhar a jogada do outro, é compreender o movimento do real. Não é um entendimento perpetrado por subjetividades para a compreensão das mesmas. Não! Trata-se, em qualquer jogo, da compreensão do real, mesmo quando este é filtrado por mundanizações.

Numa trama o comparecimento da ação - drama - é imprescindível. A ação do homem é limite mundano pra um agenciamento que o homem não pode e nem poderá dominar, jamais. A compreensão poderá ocorrer, mas sempre de modo parcial, na parcialidade em que o real poderá se mostrar e se dizer. Presença humana e ausência humana, para o real dão no mesmo. Ele não pre-dicaria, não prejulgaria. 0 real se oculta sendo, aliás, é do mesmo modo que ele se mostra sendo.

A trama-drama do jogo é a única constância nas peripécias e vicissitudes do viver. 0 jogo, aqui referido nunca é um “mero jogo", mas é $o$ jogo das vicissitudes e peripécias que nos são trazidas pela propria dinâmica do real. 0 jogo nunca é sinônimo de des-compromisso. É sempre com-promessa do real em suas vicissitudes de realidade como possibilidades advindas do ser real ele mesmo, para 
as realizações - ações provisoriamente acabadas, mas que sempre podem se articular como a diferença do que foi para a re-núncia (anunciar a coisa) do que virá a ser, sendo como participação presente.

E o futebol? E o futebol?? E o futebol???

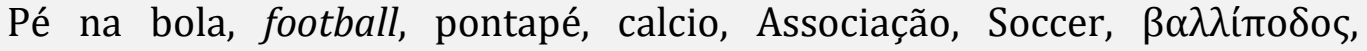
impulsionar com o pé. Em qualquer acepção em que a palavra futebol possa vir a ser compreendida, duas coisas são sempre presentes, sempre essenciais. Real e mundo, assim: mundo e imundo, aqui entendidos como ordem e desordem. Muita gente tem dificuldade em entender porque alguém é apaixonado por este jogo. Muita gente tem dificuldade em entender o porque do relacionamento apaixonado de alguns com esse jogo. Afinal, dizem alguns: é um mero jogo. Não! Não é um mero jogo. Meros jogos são todos os outros, futebol não. É muito mais que um mero jogo.

Futebol é a trama, é o drama em que real - a bola, e mundo - quem joga a bola, jogam esperando o inesperado, esperando que uma esfera, coisa-outorga desde o real, surpreenda a todos que participam deste drama. Esperando um gesto inaugural, seja ele um drible, ou o maior dos dribles, que longe de ser o gol, a meta, é o drible que uma bola é capaz de dar em quem a joga.

Recordando o nosso Ignorado de Laranjeiras, quando nos diz:

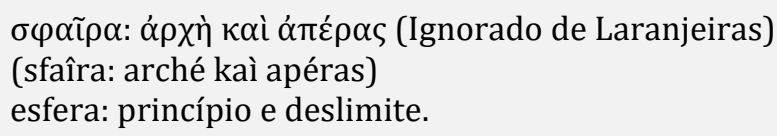

Infinidade de círculos são o princípio e o deslimite em uma inscrição na memória do gesto inesquecível, que nem sempre é o gol feito, mas muitas vezes é o gol não feito, muitas vezes é a jogada genial, outras vezes é uma jogada de uma besta, bestial - desde a besta que a realiza. Aliás, é o jogo da besta. Mais do que jogar xadres com a morte como nos tenta mostrar Ingmar Bergman no seu Sétimo Selo, o futebol dribla a morte e a vida mesmo quando desencadeia insucesso. 0 gol perdido é muitas vezes o gesto memorável, e por quê? Porque nossa memória desde o futebol preserva não o drible com a bola, mas o drible da bola, desde a bola. A bola sempre dá e sempre dará o primeiro drible. A bola é mais que um instrumento para jogar, ela é o real presentemente inesperado. Aí reside o encanto 
fundamental. Ser driblado pela bola para convidá-la para que ela se acoite, se acumplicie e então nessa trama criar o drama que, superada a primeira e decisiva dificuldade, se consiga submeter um outro qualquer, a esta altura, muito menos importante. $\mathrm{O}$ conluio com a bola produz o prazer supremo, que faz alguém que esteja singularmente acoitado com ela possa criar um espaço-tempo eônicokaiorótico em que o cronos não passa de pronúncia externa. Paixão diz concentração. Apaixonar-se é não conseguir afastar-se de uma extremada concentração e cuidado. Amar é estar em estado de paixão.

Se um dia alguém te perguntar porque amas o futebol, mostre o vídeo Watford vs Leicester - Insane moment in football. ${ }^{2}$ Terminando, como diz o amigo tricolor, Elman Torres, "ser Fluminense, ser tricolor, é esperar acontecer algo no improvável!". Aqui preciso me citar, certa vez eu disse: "não é pra falar das paixões... é apenas para vivê-las". Assim: esqueçam tudo o que eu disse acima!!!

Recebido para publicação em 19 ago. 2016

Aprovado em 02 nov. 2016

2 YouTube. Watford vs Leicester - Insane moment in football. Disponível em: $<$ http://goo.gl/h9pdDh>. Acesso em: 07 set. 2016. 